\title{
Susceptibility of three species of the genus Ostrinia (Lepidoptera: Crambidae) to Nosema pyrausta (Microsporidia: Nosematida)
}

\author{
Inna Grushevaya ${ }^{*}$, Anastasia Ignatieva, and Yuri Tokarev \\ All-Russian Institute of Plant Protection, sh. Podbelskogo 3, St. Petersburg, Pushkin 196608 Russia
}

\begin{abstract}
Microsporidia are obligate intracellular parasites that affect the population density of many insect pests. In particular, infection with Nosema pyrausta is one of the major mortality factors for the European corn borer Ostrinia nubilalis, the Asian corn borer Ostrinia furnacalis and the adzuki bean borer Ostrinia scapulalis. The purpose of the work is to compare the susceptibility to $N$. pyrausta and pathogenesis of three species of moths of the genus Ostrinia. Studies conducted over 2 years have shown that in all three species of host insects under laboratory conditions, both during oral infection and transovarian transmission of infection (in the daughter generations of experimentally infected insects), only diplokaryotic spores formed corresponding to the main morphotype of the genus Nosema. Mean lethal time increased with instar of larvae used for infection but didn't differ between the three species. The rates of transovarial transmission of $N$. pyrausta were also similar. Thus, all the insect species examined may equally participate in the parasite persistence in nature and serve as model laboratory hosts for parasitological research and mass propagation of the microsporidium.
\end{abstract}

\section{Introduction}

A study of the population biology of the European corn moth Ostrinia nubilalis (Hbn., 1796), as a dangerous pest of maize, reveals regular changes in the dynamics of insect populations, indicating the formation and gradual improvement of mechanisms for regulating its numbers in agricultural ecosystems involving maize as the main crop [1]. The expansion of corn cultivation increases the prevalence and harmfulness of the corn borer.

Screening the dynamics of $O$. nubilalis and advanced monitoring methods allow us to assess the harmfulness of the phytophagous pest in novel and established habitats and to analyze the contribution of environmental factors influencing fluctuations in its abundance $[2,3]$. To date, numerous data have been accumulated concerning the regulatory effect of a complex of entomophages and entomopathogenic microorganisms in the number of insects [4].

Microsporidia are widespread in populations of Lepidoptera being able to influence the pest dynamics $[5,6]$. For a number of mass species of lepidopteran insects, microsporidia

\footnotetext{
*Corresponding author: grushevaya 12@mail.ru
} 
act as natural regulators, including the prevention of outbreaks of mass reproduction of agricultural pests [7], such as the beet webworm Loxostege sticticalis L.,1761 [8]. The microsporidium Nosema pyrausta is virulent to the European corn borer and contributes to provocation of its depression state [9]. The entomopathogen reduces the survival rates and life span of insects, retards the development of larvae and fecundity of adults.

The influence of abiotic and biotic factors in combination with $N$. pyrausta usually have an additive effect in reducing the viability of $O$. nubilalis individuals, that is, low temperatures reduce fertility and increase larval mortality, the resistance of host plants reduces the number of larvae feeding on the plants. The use of insecticides is also more effective for density reduction of the insect host when infected with $N$. pyrausta $[10,11]$. The purpose of the work is to compare the susceptibility and pathogenesis of three species of moths of the genus Ostrinia.

\section{Materials and Methods}

\subsection{Insect cultures}

The diapausing larvae of $O$. nubilalis and the adzuki corn borer Ostrinia scapulalis (Walker, 1859) were collected in maize stands in Gulkevichsky district $(O$. nubilalis) and in cocklebur thickets in Slavyansk district (O. scapulalis) of the Krasnodar Territory in September - October 2017-2018. Live insects were transferred to a laboratory and stored at $+4^{\circ} \mathrm{C}$ in glass jars equipped with folded pieces of paper for 4 months in a refrigerator until reactivation and laboratory experiments. In the spring, reactivation was carried out, emerged adults were placed in separate containers for mating and oviposition. Egglays with blackened head capsules of unhatched larvae were placed in glass jars with artificial diet made of cornmeal, wheat germ, yeast extract and solidified with agar [12]. Ostrinia furnacalis (Guenee, 1854) eggs were provided from a permanent laboratory insect culture by the China Institute for Plant Protection, Beijing, China. For insects of this population, reactivation was not needed; they developed without diapause in the laboratory all year round.

\subsection{Microsporidia isolation and insect bioassays}

To isolate microsporidia from the stem borers of the genus Ostrinia, collected in nature, hybernating and perished larvae were examined. Dead insects were dissected and smears of the adipose body and salivary glands were examined under a light microscope. When microsporidia spores were detected, the infected tissues were homogenized and centrifuged at $4000 \mathrm{~g}$ for 5 minutes. The supernatant was decanted, the precipitate was resuspended in 1 $\mathrm{ml}$ of distilled water, and the spore concentration in the Goryaev chamber was calculated [13]. For artificial infection, II, III, and IV instar larvae and N. pyrausta spores at a dosage of $10^{5}$ spores per larvae were used. The larvae 1-3 days after molting were planted on a piece of paper folded in several layers in a hermetically sealed container for 2-4 hours without food. Microsporidia spores of $N$. pyrausta were mixed with a portion of a standard artificial nutrient medium (IPA) and provided to the larvae. After complete consumption of the spore-contaminated diet. Insects were transferred into a jar with parasite-free diet and maintained at the temperature of $+24^{\circ} \mathrm{C}$ and 18L: $6 \mathrm{D}$ photoperiod for 30 days. Mortality was recorded daily, perished were used for microscopic analysis [13]. Survived insects were used to obtain filial generation and transovarial transmission rates were estimated on the basis of microsporidia prevalence data in the filial generation. The statistical analysis of mortality rates was performed using one-way ANOVA (Holm-Sidak test), prevalence rates 
of microsporidia in progeny of artificially infected insects (transovarial transmission rates) were compared by Pearson chi-square test and median lethal time was calculated and compared using Kaplan-Meier's logrank test.

\section{Results and Discussion}

In our work, we wanted to check whether there are qualitative and quantitative differences in the pathogenesis of microsporidiosis between species of the genus Ostrinia. In particular, earlier in the course of studies, in addition to diplokaryotic spores, monokaryotic spores of microsporidia belonging to the same species, namely $N$. pyrausta, were discovered. The formation of additional sporogony is characteristic of various taxa of microsporidia, including a number of species of the genus Nosema, and weather conditions, long-term dynamics of the number of host insects, etc. are indicated as possible factors affecting the morphogenesis of parasites [14-16]. Monokaryotic spores were found in O. nubilalis, and further experiments showing their infectivity were performed on O. furnacalis. For this reason, the revealed switching of this morphotype to a regular developmental sequence leading to diplokaryotic spores [13] could occur due to the host shift. It was therefore important to study the morphogenesis of the parasite in all accessible species of the genus Ostrinia. Studies conducted over 2 years have shown that in all three species of the host insects under laboratory conditions, both during oral infection and transovarian transmission of infection (in the filial generation of experimentally infected insects), only diplokaryotic spores were formed corresponding to the main morphotype of the genus Nosema.

Main infection sites of the microsporidium were the adipose tissue and salivary glands in all three species. When II, III and IV instar larvae of the three Ostrinia species were treated with orally administered spores, total mortality substantially decreased with age. II instar larvae perished at the rate of $100 \% 30$ days post treatment. Mortality of III and IV instar larvae reached $70-76 \%$ and 53-57 \%, respectively. The differences in the mean values among the species assayed within each of the age group were not great enough to be statistically significant.

As expected, mean lethal time increased with age (larval instar) in all the three species assayed, reaching about 15, 20.5 and 25.5 days in II, III and IV instar larvae. Only slight differences were observed between $O$. nubilalis, $O$. scapulalis and $O$. furnacalis, displaying no statistically significant differences (Table 1).

Table 1. Virulence of Nosema pyrausta to three species of the genus Ostrinia

\begin{tabular}{|c|c|c|c|c|c|c|}
\hline \multirow{2}{*}{$\begin{array}{c}\text { Insect } \\
\text { species }\end{array}$} & \multicolumn{3}{|c|}{$\begin{array}{c}\text { Mortality within } 30 \text { days post } \\
\text { treatment of larvae, } \% \pm \text { SE }\end{array}$} & \multicolumn{3}{c|}{ Mean lethal time, days \pm SE } \\
\cline { 2 - 7 } & II instar & III instar & IV instar & II instar & III instar & IV instar \\
\hline $\begin{array}{c}\text { Ostrinia } \\
\text { nubilalis }\end{array}$ & 100 & $70 \pm 5.77$ & $53 \pm 3.33$ & $15.2 \pm 1.27$ & $19.9 \pm 1.62$ & $25.0 \pm 1.15$ \\
\hline $\begin{array}{c}\text { Ostrinia } \\
\text { scapulalis }\end{array}$ & 100 & $76 \pm 3.33$ & $57 \pm 6.67$ & $14.8 \pm 1.22$ & $20.0 \pm 1.45$ & $25.5 \pm 0.98$ \\
\hline $\begin{array}{c}\text { Ostrinia } \\
\text { furnacalis }\end{array}$ & 100 & $73 \pm 6.67$ & $57 \pm 3.33$ & $14.5 \pm 1.34$ & $21.4 \pm 1.46$ & $26.1 \pm 0.91$ \\
\hline
\end{tabular}

SE - Standard error

When survived part of the experimental cultures infected with microsporidia (fed with sporesas IV instar larvae) transited to adults and progeny was obtained, mid-instar larvae showed $53.6 \%(\mathrm{~N}=28), 36.3 \%(\mathrm{~N}=33)$ and $48.0 \%(\mathrm{~N}=25)$ microsporidia prevalence rates in $O$. nubilalis, $O$. scapulalis and $O$. furnacalis, respectively. Again, the values were not statistically significant when compared between the three species. 
Thus, the corn borer species examined display similar levels of susceptibility to $N$. pyrausta fairly corresponding to the relatedness levels of these three insect hosts. They may therefore equally participate in the parasite persistence in nature. Moreover, all these species may serve as suitable model laboratory hosts for parasitological research and mass propagation of the microsporidium.

The research is supported by the Russian Science Foundation, grant \# 20-66-49006.

\section{References}

1. A.N. Frolov, Plant Protection News 3(101), 4-33 (2019) https://doi.org/10.31993/2308-64592019-3(101)-4-33

2. A.N. Frolov, T.A. Ryabchinskaya, Plant Protection News 1(95), 5-11 (2018) https://doi.org/10.31993/2308-6459-2019-3(101)-4-33

3. I.V. Grushevaya, A.G. Kononchuk, S.M. Malysh, A.A. Miltsyn, A.N. Frolov, Plant Protection News 4 (102), $49-54$ (2019) https://doi.org/10.31993/2308-6459-2019-4-102-49-54

4. L. Folcher, D. Bourguet, D. Thiéry, L. Pélozuelo, M. Phalip, A. Weissenberger, M. Delos, PloS ONE. 6 (9) (2011) https://doi.org/10.1371/journal.pone.0025374

5. R.A. Simoes, J.R. Feliciano, L.F. Solter, I.Jr. Delalibera, J. Invertebr. Pathol. 129, 7-12. (2015) https://doi.org/10.1016/j.jip.2015.05.006

6. L.F Solter, J.V. Maddox, M.L. McManus, J. Invertebr. Pathol. 69, 135-150. (1997) https://doi.org/10.1006/jipa.1996.4650

7. J.J. Becnel, T.G. Andreadis, Microsporidia: Pathogens of Opportunity. First Ed. West Sussex: Wiley Blackwell. 521-570 (2014) https://doi.org/10.1002/9781118395264.ch21

8. J.M. Malysh, A.G. Kononchuk, A.N. Frolov, Plant Protection News 2(100), 45-51 (2019) https://doi.org/10.31993/2308-6459-2019-2(100)-45-51

9. J.P. Siegel, J.V. Maddox, W.G. Ruesink, J. Invertebr. Pathol. 52, 130-136. (1988) https://doi.org/10.1016/0022-2011(88)90111-5

10. L.C. Lewis, D.J. Bruck, J.R. Prasifka, E.S. Raun Biol. Contr. 48(3), 223-231. (2009) https://doi.org/10.1016/j.biocontrol.2008.10.009

11. G. Zimmermann, A.M. Huger, G.A. Langenbruch, R.G. Kleespies, J. Pest Sci. 89(2), 329-346 (2016) https://doi.org/10.1007/s10340-016-0749-4

12. A.N. Frolov, M.N. Berim, I.V. Grushevaya, Plant Protection News 3(101), 58-62. (2019) https://doi.org/10.31993/2308-6459-2019-3(101)-58-62

13. I.V. Grushevaya, A.N. Ignatieva, S.M. Malysh, I.V. Senderskiy, I.V. Zubarev, A.G. Kononchuk, Acta Protozoologica 57, 49-52 (2018) https://doi.org/10.4467/16890027AP.18.004.8398

14. G. Kyei-Poku, Y.Y. Sokolova, J Invertebr Pathol. 143, 90-103 (2017) https://doi.org/10.1016/j.jip.2016.12.003

15. G.D. Stentiford, K.S. Bateman, S.W. Feist, E. Chambers, D.M. Stone, Int. J. Parasitol. 43 (5), 339-52 (2013) https://doi.org/10.1016/j.ijpara.2012.11.010

16. Y. Wang, X.C. Li, G. Fu, S. Zhao, Y. Chen, H. Wang, T. Chen, J. Zhou, W. Fang, Eur. J. Protistol. 61 (Pt A), 122-136 (2017) https://doi.org/10.1016/j.ejop.2017.09.008 